\title{
ĐÁNH GIÁ KẾT QUẢ ĐIỀU TR!̣ BỎNG TẠI BỆNH VIỆN NHI THANH HÓA TỪ THÁNG 7/2013 ĐẾN THÁNG 6/2014
}

Nguyễn Viết Hải ${ }^{1}$, Nguyễn Thị Thu Hoài

\section{TÓM TẮT NGHIÊN CƯU}

Mục tiêu: Mô tả một số đặc điểm dịch tễ học bỏng trẻ em điểu trị tại Bệnh viện Nhi Thanh Hóa; Đánh giá kết quả buớc đâu chăm sóc và điều trị bỏng tại Bệnh viện Nhi Thanh Hóa tù tháng 7/2013 đến tháng 6/2014.

Đối tượng và phương pháp: 264 bệnh nhân bỏng được diểu trị tại Bệnh viện Nhi Thanh Hóa từ 01/7/2013 đến 31/6/2014; Phương pháp: Mô tả cắt ngang, hôi cứu;

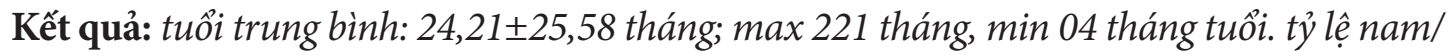

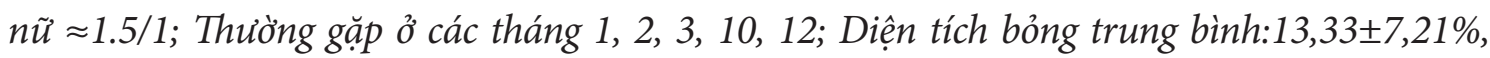
max 35.0\%; Bỏng độ I - II chiếm 63.64\%, độ II - III chiếm 35.61\%; Tác nhân gây bỏng chủ yếu là nước sôi 233 BN (88.26\%); Ghép da tụi thân 39 BN (14.8\%); Thời gian nằm viện trung binh:

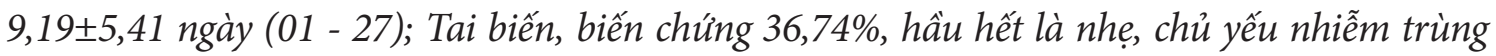
tại chỗ; Không có tủ vong; BN khỏi bệnh và tiến triên tốt $88.26 \%$, sẹo xấu 9.47\%, chuyên tuyến trên $2.27 \%$.

Kết luận: Bỏng trẻ em là một cấp cưu thuiơng gặp, điêu trị tại Bệnh viện Nhi Thanh Hóa cho kết quả tốt: không tử vong, biến chứng nhẹ.

Từ khóa: bỏng, nạn nhân bỏng, Bệnh viện Nhi Thanh Hóa, ghép da tự thân, vật liệu thay băng.

\section{Abstract}

\section{RESULT EVALUATION OF BURN TREATMENT AT THE THANH HOA} PEDIATRIC HOSPITAL FROM JULY 2013 TO JUNE 2014

Objectives: To describe some epidemiological characteristics of burns in children treated at Thanh Hoa Pediatric Hospital; Evaluation of initial results of burn care and treatment at Thanh Hoa Pediatric Hospital from July 2013 to June 2014.

\footnotetext{
${ }^{1}$ Bệnh viện Nhi Thanh Hóa 
Materials and methods: 264 burn patients were treated at Thanh Hoa Pediatric Hospital from July 1, 2013 to June 31, 2014; Methods: Description of cross section, retrospective;

Results: Average age: $24.21 \pm 25.58$ months; max 221 months, min 04 months old. Male/ female ratio $\approx 1.5 / 1$; Common in months 1, 2, 3, 10, 12; Average area of burns: $13.33 \pm 7.21 \%$, max 35.0\%; I - II degree burns accounted for 63.64\%, II - III degree burns 35.61\%; The main cause of burns is boiling water 233 patients (88.26\%); Self-grafts skin 39 patients (14.8\%); Average hospitalization time: $9.19 \pm 5.41$ days (01 - 27); Complications 36.74\%, mostly mild, mainly local infections; There were no deaths; Patients recovered and progressed well 88.26\%, bad scars $9.47 \%$, referrals over $2.27 \%$.

Conclusions: Child burns are a common emergency. Treatment at Thanh Hoa Pediatric Hospital was good results: no death, minor complications.

Keywords: burns, burn patient, Thanh Hoa Pediatric Hospital, autologous skin grafts, bandages

\section{I. ĐẠT VẤN ĐẾ}

Bỏng là tổn thương cấp tính mô tế bào gây nên bởi sức nhiệt, hoá chất, bức xạ $[1,4]$. Bỏng là một tai nạn thường gặp trong sinh hoạt, trong đời sống hàng ngày và cả hoạt động vui chơi giải trí. Bỏng để lại hậu quả nặng nề về tính mạng, sức khoẻ, chức năng, thẩm mỹ cho nạn nhân, để lại gánh nặng về tinh thần và kinh tế cho gia đình nạn nhân và xã hội. Ở Việt Nam, số bệnh nhân do tai nạn bỏng đứng hàng thứ hai chỉ sau tai nạn giao thông với 15.00016.000 bệnh nhân hàng năm.

Bỏng trẻ em chiếm từ 38,6 - 65,8\% tổng số nạn nhân bỏng. Diễn biến bỏng trẻ em nặng và phức tạp, tỷ lệ tử vong dao động từ 5 - 15\%, tỷ lệ di chứng tương đối lớn từ $20-25 \%[3,4]$.

Việc điều trị và cấp cứu nạn nhân bỏng, nhất là bỏng trẻ em trong những năm gần đây có rất nhiều tiến bộ nhờ ứng dụng các kỹ thuật mới trong cấp cứu, chăm sóc và điều trị. Tuy nhiên, chưa có một nghiên cứu nào có tính khái quát về dịch tễ và đánh giá kết quả điều trị bỏng tại Thanh Hóa.
Vì vậy, chúng tôi nghiên cứu đề tài "Đánh giá kết quả điêu trị bỏng tại Bệnh viện Nhi Thanh Hóa, tù tháng 7/2013 đến tháng 6/2014" nhằm các mục tiêu sau:

+ Mô tả một số đặc điêm dịch tễ học bỏng trẻ em điêu trị tại Bệnh viện Nhi Thanh Hóa;

+ Đánh giá kết quả bước đầu chăm sóc và diều trị bỏng tại Bệnh viện Nhi Thanh Hóa tù tháng 7/2013 đến tháng 6/2014.

\section{II. ĐỐl TUỢNG VÀ PHUOONG PHÁP}

Đối tượng: 264 bệnh nhân bỏng được điêu trị tại Bệnh viện Nhi Thanh Hóa từ 01/7/2013 đến 31/6/2014.

Phương pháp: Mô tả cắt ngang, hồi cứu, tiến cứu; tất cả bệnh nhân được nghiên cứu theo một mẫu bệnh án thống nhất.

\section{KẾT QUẢ}

- Trong thời gian nghiên cứu từ tháng 7/2013 đến tháng 6/2014, có 264 bệnh nhân được nhập viện điêu trị, tuổi trung bình: 24,21 $\pm 25,58$ tháng (221 - 04); Nam 155; nữ 109; tỷ lệ nam/nữ $\approx 1.5 / 1$; tất cả các tháng 
trong năm đều có bệnh nhân, nhiều ở tháng $3,4,10,12$. Thời gian từ khi bị tai nạn đến lúc vào viện chủ yếu trước 6h: 186 (70.45\%), sau 24 h có $49 \mathrm{BN}$ (18.56\%).

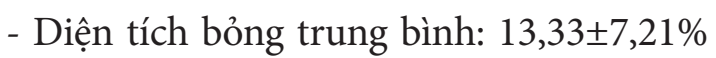
(35- 01 ), bỏng dưới $16 \%$ diện tích cơ thể chiếm $77.0 \%$ tổng số $\mathrm{BN}$ (177); có $7 \mathrm{BN}$ diện tích bỏng trên 30\% (2,7\%).

- Độ bỏng: Hầu hết là bỏng nông Độ I - II: 168BN (63.64\%); Độ II - III: 94BN (35.61\%); Độ IV: 2BN (0.76\%).

- Có 55 BN có biểu hiện sốc trên lâm sàng khi vào viện, trong đó không có sốc nặng, có
$44 \mathrm{BN}$ sốc nhẹ (16.7\%) và $11 \mathrm{BN}$ sốc trung bình (4.2\%). $5 \mathrm{BN}$ thở máy.

- Số lượng BN phải ghép da tự thân 39 BN (14.8\%), không có $\mathrm{BN}$ phải ghép da lân 2 trở lên.

- Vật liệu thay băng được sử dụng chủ yếu bằng gạc vô trùng có betadin làm ẩm với 215 $\mathrm{BN}$ (81.4\%), mỡ kháng sinh tại chỗ; có 49 BN sử dụng vật liệu hỗn hợp gồm trung bì da lợn, băng urgotul, băng mỡ sulfadiazin (18.6\%).

- Tai biến, biến chứng 36,74\%, hầu hết là nhẹ, chảy máu tiêu hóa và viêm đường tiết niệu cùng $2.06 \%$, viêm hô hấp $6 \mathrm{BN}(6.19 \%)$, nhiễm trùng tại chỗ $87 \mathrm{BN}$ (89.69\% tổng số biến chứng)

- Thời gian nằm viện:

Biểu đồ 1 . Thời gian nằm viện trung bình: $9,19 \pm 5,41$ ngày (27-1)

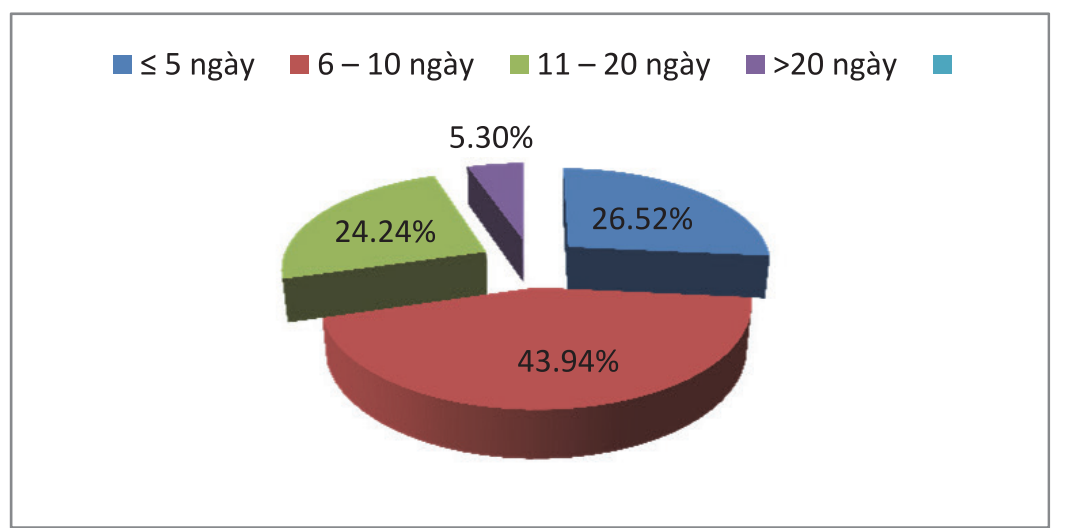

- Kết quả điều trị:

\section{Biểu đồ 2. Kết quả điều trị}

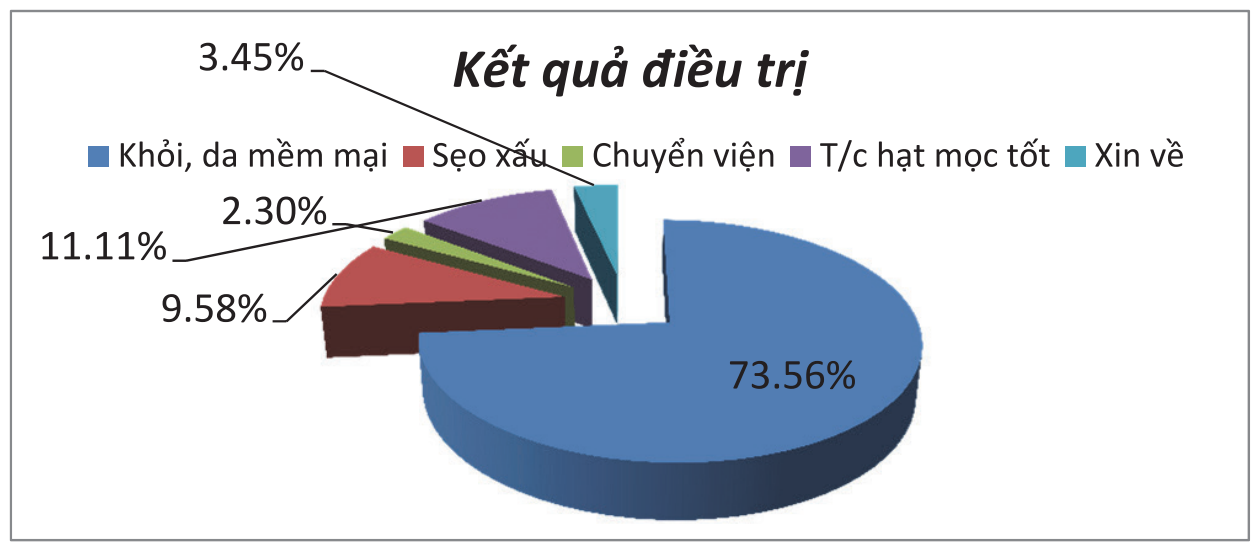




\section{BÀN LUÂ̂N}

Thống kê ở nghiên cứu này cho thấy trong vòng một năm số bệnh nhi bị tai nạn bỏng chiếm tỷ lệ $11.27 \%$ tổng số bệnh nhân điều trị tại khoa Chấn thương chỉnh hình Bệnh viện Nhi Thanh Hóa (2.341 BN).

Tuổi trung bình $24,21 \pm 25,58$ tháng, dưới 60 tháng có 249 bệnh nhân chiếm tỷ lệ 94,3\%, riêng nhóm bệnh nhân dưới 24 tháng chiếm tỷ lệ $71,6 \%$, cao hơn nhiêuu so với nghiên cứu của Hồ Thị Xuân Hương $[1,7]$. Nam/ nữ tương ứng là $58,7 \%$ và $41,3 \%$. Số liệu này tương đồng với nhiêu nghiên cứu khác về bỏng trẻ em, phù hợp với đặc điểm tâm lý trẻ và giới tính, trẻ trai thường hiếu động hơn các trẻ gái $[1,4]$.

Thời gian từ khi bị bỏng cho đến khi nhập viện trước $6 \mathrm{~h}$ có 186 bệnh nhân chiếm tỷ lệ $70.5 \%$, có 49 bệnh nhân (18,5\%) vào viện sau 24h kể từ khi bị tai nạn. Thời gian nhập viện sau bỏng trước 24h theo báo cáo của Hồ Thị Xuân Hương là 45,11\% [1], của Nguyễn Tuấn Khanh và Tạ Văn Trâm trước $6 \mathrm{~h}$ là $78 \%$, trước 24 h là $88,6 \%$ [3].

Đối với bỏng trẻ em theo phân loại của hội bỏng Hoa Kỳ thì khi diện tích bỏng > 10\% độ II là bỏng nặng và có nguy cơ sốc. Ở nghiên cứu này tỷ lệ bệnh nhân có biểu hiện sốc chiếm 20,8\% (55 BN), trong đó chủ yếu là biểu hiện sốc nhẹ, chỉ có $4,2 \%$ số $B N$ có biểu hiện sốc trung bình và nặng (trong đó có $5 \mathrm{BN}$ thở máy). Việc đánh giá và phân loại mức độ sốc chúng tôi dựa vào phân loại của Paris (19671969) trên cơ sở 8 triệu chứng, gôm: rối loạn bài niệu, $\mathrm{Hb}$ niệu, tăng ni tơ máu, nôn, áp lực TM trung ương, HA động mạch, thân nhiệt, bụng chướng [2]. Công tác hồi sức, chống sốc được triển khai tốt, có sự phối hợp giữa các khoa HSCC và khoa Chấn thương chỉnh hình, bỏng, vì vậy tất cả các $\mathrm{BN}$ đều qua giai đoạn sốc không để lại di chứng sớm. Trong nghiên cứu này chúng tôi chưa có điều kiện để tìm hiểu kỹ về điều trị sốc bỏng, hy vọng sẽ được trình bày ở các nghiên cứu tiếp theo.

Về tác nhân gây bỏng, bỏng nước sôi chiếm $88,3 \%$ và đều do tai nạn sinh hoạt, do thiếu cẩn thận khi chăm sóc trẻ gây ra. Tỷ lệ này phù hợp với nhiều nghiên cứu ở trong và ngoài nước. Diện tích bỏng trung bình ở nhóm bệnh nhân nghiên cứu là $13,33 \pm 7,21 \%$ (35-1), nhóm bệnh nhân có diện tích bỏng từ 16 đến dưới $30 \%$ diện tích da chiếm tỷ lệ tương đối cao 40,5\%. Nhóm bệnh nhân có diện tích bỏng > $30 \%$ diện tích da chiếm 33\%. Như vậy về tổng thể hâu hết bệnh nhân vào viện là trong nhóm có thể phân loại là nặng, tuy nhiên trong thực tế một bệnh nhân bị bỏng thì diện tích bỏng không thuân nhất về độ sâu vì vậy tương đối nhiêu bệnh nhân biểu hiện lâm sàng không quá nặng. Tỷ lệ bệnh nhân có diện tích bỏng $<16 \%$ chỉ có $26,5 \%$. Ở các báo cáo của các tác giả khác tỷ lệ dưới $10 \%$ diện tích da chiếm tỷ trọng lớn (gần 61\%) [5]. Về độ sâu bỏng, có 168 bệnh nhân bỏng độ I - II chiếm 63,6\%, chỉ có 2 trường hợp bỏng sâu độ IV là do bỏng lửa, một nghiên cứu của Nguyễn Tuấn Khanh và Tạ Văn Trầm tại Bệnh viện Đa khoa Tiên Giang cho đối tượng cả người lớn và trẻ em bỏng độ I, II là 85.4\% [3]. Như vậy ở nhóm BN nghiên cứu chủ yếu là bỏng nông, phù hợp với tác nhân gây bỏng hầu hết là nước sôi dự trữ trong các phương tiện sinh hoạt trong gia đình có nhiệt độ dưới $100^{\circ} \mathrm{C}$.

Có một tỷ lệ không nhỏ bệnh nhân có biểu hiện sốc với $55 \mathrm{BN}$ (20.8\%), trong đó có $5 \mathrm{BN}$ thở máy cần hôi sức và chống sốc tích cực, số $\mathrm{BN}$ có biểu hiện sốc được xử trí bằng giảm đau, truyền dịch, che phủ vết bỏng tốt là bệnh nhân đã ổn định. Chúng tôi cho rằng số $\mathrm{BN}$ có biểu hiện sốc này chủ yếu do sơ cứu ban đâu chưa tốt, đặc biệt là công tác chống đau cho BN bỏng không được quan tâm đúng mức. 
Tỷ lệ bệnh nhân phải ghép da tự thân che phủ vết bỏng là $14.8 \%$, số $\mathrm{BN}$ phải ghép da là do độ sâu bỏng từ độ III và các bệnh nhân đến viện muộn, có biến chứng nhiễm trùng tại chỗ nặng. Việc thực hiện ghép da tự thân làm ngắn quá trình điều trị và hạn chế các di chứng sau bỏng như sẹo xấu, co kéo. Có một số ít bệnh nhân được sử dụng trung bì da lợn che phủ vết bỏng ngay từ đầu đối với các bệnh nhân bỏng nông có kết quả tốt với một lần che phủ không phải thay băng nhiều lần. Việc che phủ vết bỏng bằng trung bì da lợn có tác dụng hạn chế viêm nề vết thương, giảm tiết dịch và giảm đau, phù hợp với các nghiên cứu của Hồ Thị Xuân Hương và Nguyễn Viết Lượng $[1,4]$.

- Thời gian nằm viện trung bình của nhóm bệnh nhân nghiên cứu là $9.19 \pm 5.41$ ngày. Nghiên cứu của Hồ Thị Xuân Hương khi sử dụng trung bì da lợn bảo quản lạnh sâu là 7.5 \pm 1.4 ngày [2], nghiên cứu của Nguyễn Viết Lượng ở nhóm bệnh nhân bỏng trung bì và bỏng sâu thì thời gian nằm viện trung bình là $14.06 \pm 0.36$ ngày [5].

- Tai biến, biến chứng: chủ yếu là các biến chứng nhẹ như nhiễm trùng tại chỗ, viêm hô hấp, viêm tiết niệu. Chỉ có $02 \mathrm{BN}$ có biến chứng chảy máu tiêu hóa do sốc và diện tích bỏng rộng, cấp cứu và điêu trị tích cực cả $2 \mathrm{BN}$ đêu hồi phục tốt. Chúng tôi cho rằng việc các biến chứng ở nhóm $\mathrm{BN}$ nghiên cứu chủ yếu là biến chứng nhẹ có 2 nguyên nhân: thứ nhất, đa số các bệnh nhân có diện tích bỏng nông và được sơ cứu cấp cứu tương đối hợp lý. Thứ hai, việc triển khai cấp cứu, điều trị toàn thân và tại chỗ cho từng bệnh nhân được thực hiện theo đúng quy trình kỹ thuật, các kỹ thuật mới được áp dụng, phối hợp giữa các bộ phận trong quá trình điêu trị tương đối đồng bộ.

- Kết quả điêu trị: không có bệnh nhân tử vong trong tổng số $264 \mathrm{BN}$ điều trị tại bệnh viện trong suốt 01 năm, báo cáo của Hồ Thị Xuân Hương tử vong tại viện bỏng quốc gia năm 2007 là 1,56\%, số liệu của chúng tôi tương tự như báo cáo của Nguyễn Viết Lượng, Nguyễn Tuấn Khanh $[3,5,6]$. Chỉ có $6 \mathrm{BN}$ $(2,27 \%)$ chuyển tuyến trên điêu trị, trong đó có $03 \mathrm{BN}$ chuyển tuyến theo yêu cầu và do $\mathrm{BN}$ là người Hà Nội. Việc tỷ lệ chuyển tuyến thấp đã gián tiếp khẳng định khả năng cấp cứu, điêu trị bỏng trẻ em của các bác sĩ, điều dưỡng của bệnh viện. Số BN có tổ chức hạt mọc tốt do xin ra viện sớm ở ngày thứ 3 , thứ 4 và số $B N$ điều trị ngoại trú chúng tôi xếp và nhóm $\mathrm{BN}$ khỏi, liên sẹo tốt, chiếm tỷ lệ $88,25 \%$, có 25 BN $(9,47 \%)$ liền sẹo xấu có khả năng để lại di chứng sau bỏng, phần lớn là bỏng ở vùng bàn tay, bàn chân, các nếp gấp.

\section{KẾT LUẬN}

- Tỷ lệ bệnh nhân bỏng điều trị tại khoa Ngoại Chấn thương chỉnh hình bằng $11.27 \%$ tổng số $\mathrm{BN}$ điêu trị hàng năm và bằng $0.88 \%$ tổng số BN nội trú toàn viện hàng năm;

- Tuổi BN dưới 5 tuổi là chủ yếu trong đó dưới 2 tuổi $71.6 \%$; Tỷ lệ $\mathrm{BN}$ nam/nũ là 1,5/1; Tất cả các tháng trong năm đều có $\mathrm{BN}$ bỏng, tập trung nhiêu ở các tháng mùa lạnh;

- Tác nhân gây bỏng hâuu hết là nhiệt ướt, trong đó nước sôi là nguyên nhân chính với $88,26 \%$;

- Tỷ lệ ghép da tự thân che phủ tổn thương bỏng là 14.8\%;

- Thời gian nằm viện trung bình $9.19 \pm 5.41$ ngày; tỷ lệ biến chứng $36.74 \%$ nhưng chủ yếu là biến chứng nhẹ: nhiễm trùng tại chỗ, viêm hô hấp...;

- Không có tử vong; BN khỏi bệnh và tiến triển tốt $88.26 \%$, sẹo xấu $9.47 \%$, chuyển tuyến trên $2.27 \%$. 


\section{TÀI LIẸU THAM KHẢO:}

1. Hồ Thị Xuân Hương (2009). Dịch tễ bỏng trẻ em 23 năm (01/1985-12/2007) tại Viện bỏng Quốc gia Việt Nam; Tạp chi Y học thực hành số 562+563-2009, tr 14-19;

2. Hồ Thị Xuân Hương (2010). Nghiên cứu tác dụng của trung bì da lợn bảo quản lạnh sâu trên vết thương bỏng nông trẻ em; Tạp chí Y học thảm họa \& Bỏng số 2/2010; tr 45-52

3. Nguyễn Tuấn Khanh, Tạ Văn Trầm (2009). Nghiên cứu đặc điểm dịch tễ học, chẩn đoán và điều trị bỏng tại Bệnh viện Đa khoa Tiền Giang năm 2007; Tạp chi Y học thực hành số 562+563-2009, tr 27-29;

4. Nguyễn Viết Lượng (2009). Tình hình bỏng tại Việt Nam trong 3 năm (2005 - 2007); Tap chí Y hoc thực hành số 562+563-2009, tr 9-13;

5. Nguyễn Viết Lượng, Nguyễn Hồng Thái (2009). Đánh giá tác dụng của trung bì da lợn bảo quản lạnh sâu trong điều trị tại chỗ tổn thương bỏng trung bì và bỏng sâu toàn bộ lớp da tại Viện bỏng Quốc gia; Tạp chi Y học thực hành số 562+563-2009, tr 121-131;

6. Lê Thế Trung (2003). Bỏng, nhũng kiến thức chuyên ngành. NXB Y học.

7. Viện Bỏng Quốc gia (2006). Sơ cúu, cấp cúu và điều trị bỏng, NXB Y học, tr 9-42; 